\title{
Size-assortative mating in the earthworm Eisenia fetida (Oligochaeta, Lumbricidae)
}

\begin{abstract}
In many species of simultaneous hermaphrodites, body size correlates with fecundity, and larger partners are preferred to small ones. Since sperm exchange is usually reciprocal, small individuals may be rejected by larger partners resulting in size-assortative mating. We studied the mating patterns in a natural population of the simultaneous hermaphroditic earthworm Eisenia fetida (Oligochaeta, Lumbricidae). We found that size-assortative mating processes existed, with variance in body weight within pairs lower than between pairs in mating earthworms. This nonrandom mating pattern probably reveals the existence of mate selection in this species, which lives at elevated densities with high availability of potential mates.
\end{abstract}

Key words Earthworms - Eisenia fetida - Mate selection . Simultaneous hermaphrodites $\cdot$ Size-assortative mating

\section{Introduction}

In animals, the mating pattern depends on population density, availability of mates, mating preferences and competition over number of mates (Jennions and Petrie 1997). Mate selection on body size has been proposed as a major force for the mating patterns found in nature (Ridley 1983). In particular, mating strategies of simultaneous hermaphrodites may depend on body size because the fecundity of the female function is normally limited by the available energy invested in egg production, while the fecundity of the male function is normally limited by the availability of eggs (Charnov 1979). In fact, in many species of simultaneous hermaphrodites, body size correlates with fecundity, and larger partners are preferred to smaller ones (Vreys and Michiels 1997; Lüscher and Wedekind 2002). Since sperm

F. Monroy $(\bowtie) \cdot$ M. Aira $\cdot$ A. Velando $\cdot$ J. Domínguez Departamento de Ecoloxía e Bioloxía Animal, Universidade de Vigo, Vigo, 36310, Spain

Tel. +34-986-812593; Fax +34-986-812556

e-mail: monroy@uvigo.es exchange is usually reciprocal, small individuals may be rejected by larger partners resulting in size-assortative mating (Ridley 1983).

Earthworms are a widespread group of simultaneously hermaphroditic animals with reciprocal insemination (Edwards and Bohlen 1996). In some species of earthworms occurring at high densities, size-assortative mating may be predicted because availability of mates is high, but mating is costly (Michiels et al. 2001). Size-assortative mating has been studied only in one species of earthworm, Lumbricus terrestris Linnaeus 1758 (Clark 1941; Michiels et al. 2001). In an experimental study, earthworms preferred same sized mates to differently sized ones, suggesting a precopulatory mate assessment (Michiels et al. 2001). No further studies on size-assortative mating have been conducted in earthworms. Eisenia fetida (Savigny 1826) is an earthworm that lives in manure heaps in high densities (up to 3,000 individuals $/ \mathrm{m}^{2}$ ), thus offering considerable potential for exercising mate choice. Moreover, the mating process is expected to be costly because they spend a long time in copulation (Grove and Cowley 1926), and in addition the mucus and sperm production as well as the constriction movements between partners are energy draining. The aim of this study was to test the occurrence of size-assortative mating in the earthworm E. fetida in a natural population.

\section{Materials and methods}

Pairs of mating earthworms $(n=104)$ were collected in a dung heap of cow manure from a small farm near the University of Vigo $\left(42^{\circ} 9^{\prime} \mathrm{N}, 8^{\circ} 41^{\prime} \mathrm{W}\right)$, in the northwest of Spain. Individuals were collected by the hand-sorting method (Edwards and Bohlen 1996) in June 2000. Each partner was weighed (fresh weight) in the laboratory and within-pair weights were compared using a one-way ANOVA with pair number as a factor to test the occurrence of assortative mating by size. The correlation of within-pair weight was derived from the intraclass correlation coefficient $\left(r_{i}\right)$ (Lessells and Boag 1987). 


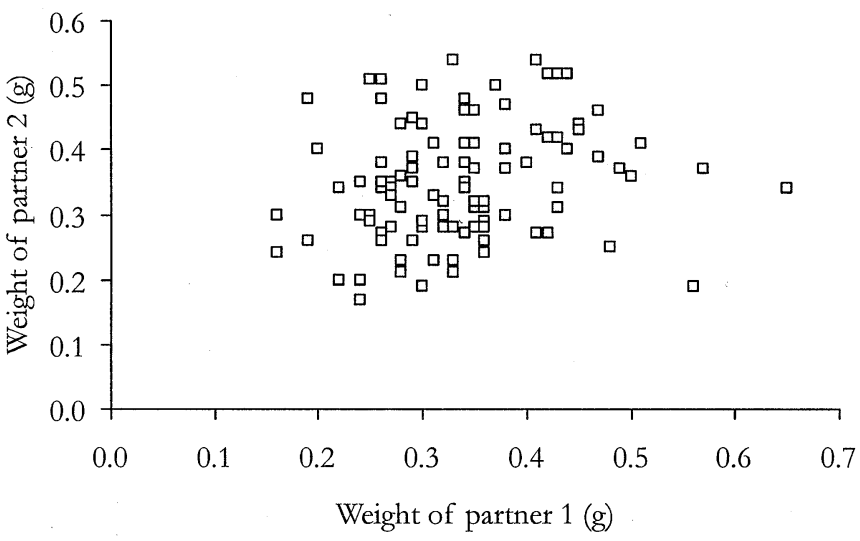

Fig. 1. Relationship between the body weight of the partners in mating pairs of earthworms collected in a natural population of Eisenia fetida in spring ( $n=104$ pairs). Partners' weights were randomly assigned as partner 1 or 2

\section{Results}

Body weight of adult mating earthworms ranged from 0.16 to $0.65 \mathrm{~g}$, with a mean value of $0.34 \pm 0.09 \mathrm{~g}$. The average weight proportion of within pairs earthworms was $1: 1.32$, and the maximum difference in weight between partners was $0.19: 0.56 \mathrm{~g}(1: 2.95)$.

The analysis of the collected set of mating earthworms revealed that the variance in body weight within pairs was lower than between pairs (ANOVA $F_{103,104}=1.49, P=$ $0.021)$. The intraclass correlation coefficient showed a value $r_{i}=0.20$ indicating assortative mating by size. The weight of the partners within a pair was similar and showed a positive relationship (Fig. 1).

\section{Discussion}

This is the first study of mating patterns in the earthworm E. fetida. We found size-assortative mating in a natural population of this species and these non-random mating patterns probably reveal the existence of mate selection. Ridley (1983) predicted that assortative mating by size in simultaneous hermaphrodites occurs in species with reciprocal fertilisation and in which larger individuals lay more eggs. E. fetida shows reciprocal sperm exchange during copulation (Grove and Cowley 1926; Domínguez et al. 2004) and larger individuals within mating pairs produce more cocoons (Meyer and Bouwman 1997). In another study of mate choice in earthworms, L. terrestris showed preference for same-size partners in experimental conditions, while assortative mating in the field was found in some samples, but not in others (Michiels et al. 2001). The differences between the mating preferences and mating patterns can be attributed to the burrowing behaviour of L. terrestris, since this species lives in permanent burrows and mating choice is limited to the neighbourhood (Michiels et al. 2001). However, E. fetida is an epigeic species living at high densities in temporary accumulations of organic matter (e.g. manure heaps), so there is no apparent limitation on choice of mate partners. An interesting open question is how E. fetida assess the body size of the partner. Grove and Cowley (1926) suggested the existence of some kind of precopulatory behaviour or courtship in E. fetida, since they observed the occurrence of short and repeated touches between partners before mating attachment. Alternatively, it has been proposed that assortative mating could be constrained by physical incompatibility of the copula among partners of different sizes (Ridley 1983; Michiels et al. 2001). However, we found differences between partners as larger as $1: 3$. Although E. fetida showed size-assortative mating, the low intraclass correlation coefficient also indicates within-pair high variability in body weight. The within-pair variability can be due to the simultaneous assessment of several traits by the partners (Gibson and Langen 1996). More studies are required to discover whether earthworms select partners by traits other than size.

\section{References}

Charnov EL (1979) Simultaneous hermaphroditism and sexual selection. Proc Natl Acad Sci USA 76:2480-2484

Clark H (1941) Selective mating in the earthworm (Lumbricus terrestris L.). Proc Iowa Acad Sci 48:445-455

Domínguez J, Velando A, Aira M, Monroy F (2004) Uniparental reproduction of Eisenia fetida and E. andrei (Oligochaeta: Lumbricidae): evidence of self-insemination. Pedobiologia 47:530-534

Edwards CA, Bohlen PJ (1996) Biology and ecology of earthworms. Chapman and Hall, London

Gibson RM, Langen TA (1996) How do animals choose their mates? Trends Ecol Evol 11:468-470

Grove AJ, Cowley LF (1926) On the reproductive processes of the brandling worm, Eisenia foetida (Sav.). O J Microsc Sci 70:559-581

Jennions MD, Petrie M (1997) Variation in mate choice and mating preferences: a review of causes and consequences. Biol Rev Camb Phil Soc 72:283-327

Lessells CM, Boag PT (1987) Unrepeatable repeatabilities: a common mistake. Auk 104:116-121

Lüscher A, Wedekind C (2002) Size-dependent discrimination of mating partners in the simultaneous hermaphroditic cestode Schistocephalus solidus. Behav Ecol 13:254-259

Meyer WJ, Bouwman H (1997) Anisopary in compost earthworm reproductive strategies (Oligochaeta). Soil Biol Biochem 29:731-735

Michiels NK, Hohner A, Vorndran IC (2001) Precopulatory mate assessment in relation to body size in the earthworm Lumbricus terrestris: avoidance of dangerous liaisons? Behav Ecol 12:612-618

Ridley M (1983) The explanation of organic diversity. Clarendon Press, Oxford

Vreys C, Michiels NK (1997) Flatworms flatten to size up each other. Proc R Soc Lond B 264:1559-1564 